\title{
APPLIED DISCOURSE ANALYSIS: TWO ASPECTS OF POLYCULTURAL COMMUNICATION
}

\section{Filippova N. M.}

\author{
"The man is doomed to live in culture \\ as he lives in biosphere". \\ Yu. Lotman
}

\section{INTRODUCTION}

Judging from the revision of the topics discussed in linguistics for the last 25 years, we are facing the clash of cultures in the global space and, consequently, the clash of the English language and the native languages of a variety of speakers and writers all over the world. A somewhat unfortunate dichotomy prevailing worldwide means that it is quite apparent that the world changed after the English language became the first global language in the history of humanity, though more than 60 years ago R. Lado, the prominent American linguist and foreign language methodologist, accentuated the necessity of a systematic comparison of languages and cultures: "Cultural understanding. The idea that we might be able to test the understanding of a foreign culture objectively seems impossible to most people today. We know so little about the structure of our own culture, let alone that of a foreign one. And how can we compare cultures anyway"1. One of the assumptions for our applied analysis was the selection of two types of discourses as the potential platform for dealing with the differences between the culturally oriented contexts and the language which promotes their understanding adequately.

The aim of the paper is to share some primary results of the applied discourse analysis obtained in the process of accomplishing two interdisciplinary discourse-based projects at the Department of Applied Linguistics at Admiral Makarov National University of Shipbuilding: Project 1 deals with the analysis of cognitive metaphors in American media texts, the project being aimed at the development of communicative competence for Bachelors and Masters in linguistics; Project 2 deals with the analysis of

${ }^{1}$ Lado R. (1993) The necessity for systematic comparison of languages and cultures // Landmarks of American language and linguistics, vol. 1. Washington: Materials Development, p. 80. 
academic discourses for $\mathrm{PhD}$ technical students. It appeared that we faced the common challenge while collecting and processing discourses, though their being different in nature. The fact is that we had to cope, first of all, with the cross-cultural differences in the ways the authors were impacting their readers.

We stated the necessity of these projects in accordance with the following theoretical approaches.

First, it is the fact that contemporary linguistics is characterised as a polyparadigm science which is stipulated by the complex and multivector study of the variety of language phenomena. Thus among the attributes of this stage of linguistic development there are the basic three approaches: a) functional - communicative - pragmatic (language in action, i.e., in communication); b) synergistic (language as an open linear system); c) cognitive and discursive (language as a cognitive entity which is used in various discourses). Therefore linguists are trying to unite, synthesize various methods and principles for the effective interaction of communicative factors related to the language structures and cognitive factors related to mental activity.

Second, executing its communicative function, any language demonstrates that it is the most important "device" of presenting a human being as a social personality with his/her individual variations of motivations and forms of behaviour, communication being conditioned by both linguistic and extralinguistic factors (presupposition, situational preferences and, certainly, national cultural traditions) and being supported by the means of secondary semiotic systems (e.g., musical notation, mathematical signs, programme languages etc.).

Third, it is universally acknowledged that the control role in any communicative event is played by the following factors: 1) communicators (a message sender vs a message receiver with their goals, personalities, cultural differences); 2) culturally motivated communication contexts (time, place); 3) culturally marked rule-governed relationships; 4) channels (the media chosen for communication (e. g., speaking face-to-face, on the phone, in forums); 5) messages (specific genres, grammar, vocabulary, or the subject matter; 6) outcomes (the expected results of the communication).

Fourth, as a forerunner of the referential theory of communication P. Grice developed his four universal basic maxims for efficient communication: 1) the maxim of quality states the communicators' contributions to communication should be true, evident; 2) the maxim of quantity implies that the communicator contribution should be informative enough to reach the goal of communication; 3) the maxim of relevance shows that the contribution should be in line with the goal of 
communication; 4) the maxim of manner indicates that the contribution should be clear, properly structured and not excessive. He also subordinated them to the co-operative principle, together they explain why communication functions rather smoothly in spite of the fact that communication consists not only of the outspoken, the explicit information but also, and often to a considerable degree, of implicit information. The Gricean approach explains the fact why implicitly communicated information is interpreted correctly to a rather high degree though many questions arise what to do with intercultural communication ${ }^{2}$.

Fifth, even a short overview of these elements of communicative process highlights a very significant common feature: they all depend on the implied cultural and personal diversity of communicators irrespective of the fact whether they are addressers or addresses. In monocultural society communicators' cultural differences are not of top-priority importance, though they can belong to different ethnic groups or religious denominations (e. g., in Ukraine people living in the west can have somewhat different cultural and religious traditions from the people living in the east), leaving alone their differences in age, education or family background. And what about polycultural communication when people speak different first languages? In polycultural communication communication contexts are even more important (e.g., the use of pronoun forms in formal or informal communication contexts, different politeness strategies in different cultures, different nonverbal elements of communication). Multitudes of factors cause speech divergence: people want to emphasize their personal, social, religious or other identity; they show their dislike of other person's appearance or behaviour; or, what is especially notable, they express their cross-cultural differences in some way. It is also indicated that the type of activity directly impacts the way people communicate: discussing, arguing, quarreling, chatting, gossiping or writing emails, reports, messages, articles. Culture relates to the social heritage of the nation: these are the assimilated and mastered mental matrices, feelings, stereotyped actions which are transfered from generation to generation, even including these matrixes into material objects. Culture includes, at least, four obligatory components: norms, values symbols and language.

Sixth, we would like to base our assumptions on the discourse definition proposed by F.S. Batsevich who understands discourse as a special type of communicative activity, an interactive phenomenon, a stream of communication, a sum of speech acts which can be presented in oral, written

${ }^{2}$ Grice P. (1968) Studies in the way of words. - Harvard: Harvard Univ. Press. DOI 10.1163/9789004368811_003 
or paralingual forms within particular communication channels, be regulated by tactics and strategies of the participants of communication, can represent the synthesis of cognitive, linguistic and extra-linguistic factors and results in a variety of communicative genres ${ }^{3}$.

We also adhere to the sociolinguistic understanding of this term proposed by V. Karasik: a) personal discourse when a speaker represents his individual thinking, comprehension of the events or their consequences; and b) institutional discourse when a speaker formulates the views, stereotypes, values of definite social groups or institutions. In today's information society media-discourse plays the role of a mediator between the government and the people ${ }^{4}$.

Therefore the factors generating communicative process are of toppriority importance both for theory and practice. As the English language became a global language of science, culture, politics, business for the whole multicultured world, here, in Ukraine, we are very interested in understanding the differences in comprehending and generating various discourses.

\section{Written Mass Media Discourse}

From the beginning of the 1980s much has been shown concerning the influence of a separate linguistic meaning of a word upon the utterence and discourse meaning which has radically changed our understanding of semantics and made it possible to interpret lexical units as examples of both nomination and discourse: combinatorial characteristics of words and their variations are understood as meaning-building conceptual mechanisms in dynamics of the real ongoing communication (the ideas of compositional semantics developed by $\mathrm{M}$. Bierwisch and resulted in understanding concepts as operational units of conscience widened the number of cognitive strategies used by a speaker/writer in the process of comprehending and generating discourses). There is a proved evidence of conceptual integration and categorization which activate the preexistent networks in human memory, the notions like framing, metaphors, prototypes, proposition manifasting a deeper unitary operation of integration and creating "the blend" which reflects a dynamic type of socio-cultural and pragmatic model as a means of studying discourse, e. $g$. the fundamental conclusions of

\footnotetext{
${ }^{3}$ Batsevich F. S. (2004) The basics of communicative linguistics. K. : "Academia" Press.

${ }^{4}$ Karasik V. I. (2002) The language circle: personality, concepts, discourse. Volgograd: Peremena.
} 
A. Wierzhbicka ${ }^{5,6}$ on the interrelations between the ethnic, national and cultural specific mentalities and all the levels of language system.

As generally culture is understood as a wide set of relationships, traditions, customs, individual behaviour, superstitions, the universal role of the language is to reflect all the specific features of every society and to demonstrate the whole scope of the human experience in typical conditions of natural and social environment and a variety of social models of behaviour, language being the basic means of verbalization of various aspects of culture.

The applied approach to the Projects made us look at our students as twenty-first-century learners who are "plugged in", fluent with technology and motivated by social media, embrace their likes for using mass media and engage them in authentic and meaningful English language learning in a familiar and motivating context.

Project 1 was broken into some manageable chunks, the first stage consisting in collecting quality examples which, to our mind, were displayed in British and American media, and then at the second stage compare the use of conceptual metaphors in Ukrainian and English mass media discourses.

The purpose of the first stage was to attract the attention of the Project team to the fact that: 1) American media texts in English have recently become the powerful instrument for spreading the information all over the world and manipulating the conscience, social mentality, everyday experience and behaviour; 2) culture, as the universal fact of American life, demonstrates the value scale of the members of society; 3 ) lexical polysemy is the way of storing language and encyclopedic information, categorizing human experience which results in changes and transformations in the language; 4) in its turn, dynamics of language changes and transformations result in emergence of metaphors which are associative phenomena, which reflect all the changes in any society, thus constantly enriching the language, and provide the opportunity for studying the processes and results of language and cognitive mechanisms, being the means of conceptualizing empirical knowledge and performing the linguistic monitoring of social conscience and the means of foregrounding the necessary concept from the wide socio-cultural context.

As far as American mass media are concerned, they naturally reflect the ideas of culture being the basic filter between those who adhere to this

5 Wierzhbicka A. (1991) Cross-cultural pragmatics. The semantics of human interaction. Berlin - New York: Mouton de Gruyter.

${ }^{6}$ Wierzhbicka A. (1992) Semantics, culture and pragmatics. Universal human concepts in culture. Oxford: Oxford University Press. 
culture and the social, economic and political environment, at the same time, performing the protecting and limiting functions to save American traditions and values.

Moreover, mass media texts are particular stimuli for causing particular reaction of their readers as they introduce them into the broad social context which is rather subjective and which includes the context of the actual event, the ideological context and the historically motivated cultural context. Thus American culture is always reflected in the language of mass media texts: culture and language are interacting, the vocabulary being the means of enriching language conscience and feedbacking all the changes of the social life: social phenomenon > changes in the language > changes in culture.

The language means of media texts are selected and targeted at the public at large to form their values. On the one side, media discourses require and provide for general thinking skills, on the other side, the mechanism of the language influence on the mass conscience appeals to human feelings and emotions.

One of the mechanisms of targeted influence is executed: a) by highlighting one of the elements of the picture of the world presented by a particular language; b) by its being stereotyped and c) by its being introduced into some language forms which value characteristics are approaching the target subject. The comprehension of the information obtained causes the activation of sensing elements of conscience, intuition, thus enabling to reconstruct social values of subconscience ${ }^{7}$.

Readers' audience is under constant regulated and controlled influence of mass media texts which gradually result in the fundamental changes in readers' values orientations. They comprehend the information obtained as the reason for some necessary action, especially if it is directed to achieving some definite aims. At the same time the reading audience becomes the social context which is, in its turn, reflected in mass media discourses, thus building the chain: Language - Culture - Mentality - Comprehension Language.

Conceptual metaphors cause the emergence of the concept or even a chain of concepts and become the social and cognitive basis for communication because cognition is always inseparable from evaluation, and connotative associations seem directly depend on the living traditions of the speakers of this language, thus modeling comprehension. Moreover, at present conceptual metaphor is considered a specific type of modality: from the cognitive and pragmatic view it can be analysed as the category of sensegeneration and sense-perception.

${ }^{7}$ Lakoff G. (1980) Metaphors we live by. Chicago: Chicago Univ. Press. 
However, the problem for other language speakers is that conceptual metaphor only unites language, thinking and culture in its national contexts specific for particular national or ethnic cultural conscience and mentality. The bright example illustrates this statement: in his research of FITNA, one of Arab cultural constants, O. Bogomolov proves that the persuasiveness of this concept is much more powerful in comparison with other international words with the same denotational meaning, e. g. civil war or anarchy, due to the long-lasting history of functioning within religious and historical discourses: the typical communicative aim for the FITNA discourses is to prevent conflicts inside definite political or social groups, because in Arab discourses concerning war and peace, this concept symbolizes the final situation of disorder and discord which the society is aspiring to overcome or even prevent. Though these archaic images in contemporary political and social contexts seem to be tropes, their background involving cultural presuppositions keep on impacting the contemporary models of behaviour ${ }^{8}$.

Varieties of conceptualization of the world are vividly reflected in political mass media discourses. Thus J. Lakoff stated that the process of political battles in the USA convinced him that conservatives and liberals base their election platforms on different moral systems which is reflected in their political discourses. Conservatives consider the family as the patriarchal cell of the society where the main role is played by the father, the leader, the breadwinner, children having to live their own lives and having to be responsible for their actions and decisions when they grow up. Liberals, on the contrary, treat the mother as the leader in bringing children up and, consequently, children easier adapt to their becoming adult ${ }^{9}$. Therefore the words character, virtue, discipline, get tough, strong, individual responsibility, standards, authority, heritage, common sense, freedom are more frequent in conservative discourses, while the words social responsibility, human rights, equal rights, care, help, health, nutrition, biodiversity are more frequent in liberal discourses.

Particularly striking observations can be made if we use corpora and concordances data for comparison, which is especially important for the assessment of the potential influence of the first language in foreign language acquisition because when speaking a foreign language even advanced learners tend to be influenced by their first language: complexity in language learning is often created by semantic or conceptual mismatches

${ }^{8}$ Bohomolov O. V. (2019) From temptation to discord: the concept of FITNA in Arab Spring discourse // Movoznavstvo, No.1, p. 3-8.

${ }^{9}$ Lakoff G. (1996) Moral politics: What conservatives know that liberals don't. Chicago: University of Chicago Press. 
when the two languages do not coincide to cover some aspects of situations or lexicalize similar notions. For example, concordances allow us to reveal more about the actual use of words in context: compare the concordances for the lexemes different and різний in native and non-native writing and you will see that it grossly overused by Russian and Ukrainian contexts where in English contexts various or of different kinds/types/sorts of should be used.

Interesting conclusions were made by A.O. Khudoliy who concentrated on the role of metaphors as the indicators of the changes in mass media texts, i.e., the changes in nominations of reality parametres: new phenomena and objects are nominated by new words, or the existing words are adapted to new realia under the influence of changing social conditions ${ }^{10}$. A new nomination is always a new sign, a new identification of a particular fragment of the picture of the world, a new fact in transformations of the conceptual knowledge picture of the world. A. Khudoliy states that in mass media texts metaphors play at least 18 functions. For the purpose of the Project we condensed them into three basic ones:

1. Cognitive function which unites image-building for creating the conceptual image; thought-provoking as a thinking instrument; gnoseological for forming a new notion; cognitive for processing the information obtained.

2. Communicative function which unites communicative for conveying the necessary information; expressive for making the utterance expressive and for attracting the readers' attention; propaganda-promoting; pragmatic for the readers to understand the author's view; evaluative for interpreting the events or categorizing the human experience; entertaining and social for identifying the social status of the addresser.

3. Nominative function which unites nominative for creating the name for the regalia; compressive as a means of lexical economy; euphemistic because it enables to indicate those elements of the information which the author does not want to show by the appropriate nominations; stylistic for referring; onomaciological for substituting one word for another; cultural development influencing the development of the language; mnemonic for enriching and decoding the information.

Thus metaphor is considered to accomplish the functions of creating the necessary concept or notion, creating a necessary language fact and creating a means of communicative expression.

A. Khudoliy also distributed all the conceptual metaphors obtained in American mass media texts into 18 groups which clearly illustrate the

${ }^{10}$ Khudoliy A. O. (2005) Metaphor in the language of mass media texts. Ostrog: NUOA Press. 
specific symbols of American mentality: SEA, WILDERNESS, HUNTING, WAR, HUMAN BEING, ILL PERSON, GASTRONOMY, DAY/NIGHT, ROAD/WAY, SPORT, THEATRE, ART, CHEMICAL PROCESS, DIRT, EMPIRE, EDUCATION, FAMILY, METAPHORICAL and conceptual space of American mass media discourses presenting the integral political and social life of a person in American realities. According to his study, about 20 per cent of the whole number of all the metaphors registered belong to the group of conceptual metaphors SEA and ROAD/WAY which are associated with: a) intensity, dynamics, energy, unlimitedness; b) protection (in a harbour or a port); c) guidance (by a captain) or orientation to smth (lighthouses, beacons); d) stability and prosperity (the symbol of anchor) and, at the same time, with cruelty, danger, aggression, playing the leading role in the picture of American political and social life ${ }^{11}$.

In the process of conducting the Project we took a random issue of the magazine "New Yorker" (Dec. 16, 2019) and asked the team participating in this experiment to scan it and look for the metaphors scattered around the texts inside "fishing" for the metaphors used by their authors. The result was amazing - again, about 18 percent belong to SEA and ROAD/WAY metaphors, becoming the leaders among other metaphors revealed within the magazine, e. g. deep under the surface, green lights, cosmic (fantastic)book; to knock the rock, to clear the way, to stay on the right track, to hit the road, to stay afloat, to drift, to sink, to keep sailing, to rock the boat, a Channel One anchorman (Russian TV Channel One General Producer Konstantin Ernst).

Another representative group WAR can also be exemplified by a group of metaphors, e. g. attack, grab, crash, parade, salute; to fight the dragon and rescue a girl, to unlaunch the torpedo.

Moreover, the new global reality caused by the pandemic of COVID-19 is described as a sea of turmoil, a stormy sea of fear and chaos around us, finding ourselves in in the same global boat, looking for smooth sailing (easy, manageable teaching and learning), being on/off track (in online lessons or conferences).

It is notable that the same metaphoric approach is used, for example, in titling webinars which are organised during the global lockdown: Pearson presenter Graham Jones invites to visit his webinar "Meet Speakout Dive into Authentic English: Enjoy Real Communication”.

Even scholars like using the concept SEA in their publications, e. g. the prominent British linguist David Crystal headlines the article in the

${ }^{11}$ Khudoliy A. O. (2005) Metaphor in the language of mass media texts. Ostrog: NUOA Press. 
professional journal "Swimming with the tide in the sea of language change" emphasizing his ideas with this sustained conceptual metaphor throughout the whole text thus manifesting the unique vision of the problem of unpredictable change of the contemporary global English language: the constant ebb and flow of words, sounds, and structures at the tidal margins of a language, the tidal metaphor, to stop the tide coming in, no two high tides are the same, the tides are different - reaching one part of the beach today, a different part tomorrow (IATEFL Issues, July 1999, p. 2).

At the third stage of the Project it is presupposed to make the conceptual analysis of the top conceptual metaphors revealed in the discourses under discussion.

Thus the distribution of the model metaphor SEA in mass media discourses seems to enable to imagine the historical fate of the state as ship sailing or navigation, thus opening the opportunities for widening the conceptual space and including other metaphoric components (how, where, when, who, what, why, what for), the elements of the concepts could be built into the frame for presenting the mental spaces.

The fourth stage of the Project is supposed to be aimed at the comparative analysis of American and Ukrainian political discourses because culturally marked picture of the world forms the type of attitude of the man towards the world at large - the nature, other people oneself as an element of the world (we could use the metaphor "pixel of the picture of the world"). In its turn, it determines the norms of behaviour of an individual. Therefore any society is interested in the so-called "cultural transmission", i.e. in making every member of the society realize the adequate picture of the world which determines the line of behaviour the line of behaviour of each individual member and and the whole society. At this stage of the analysis we have not revealed the coincidence in the use of the concepts mentioned in Ukrainian mass media discourses.

To sum up, mass media means are aimed at modelling the world around the man; they are oriented to their addressees, causing changes in their cognitive spheres by influencing them and manipulating their conscience in a positive or negative way. Metaphors interact human cognition and semantic parametres of a language. Therefore they can be used as instruments for analysing stereotyped socio-cultural concepts.

\section{Written Academic Discourse}

The $\mathrm{PhD}$ Programme at Admiral Makarov National University of Shipbuilding was designed to help postgraduates in various technical fields to reach $\mathrm{C} 1$ level (CEFR) in Academic English, of particular interest being the development of writing skills for their professional activity. As part of 
the Programme, there was the module on Written Academic Discourse, which enabled to initiate the Project aimed at the analysis of sociocultural differences in specialist technical discourses: we were aware of the fact that postgraduates felt quite nervous when dealing with the necessity of writing specialist academic texts in English because of their initial impulse to copy the structure and composition of identical texts in Ukrainian or Russian.

Without specifying the details of methods and materials used, let's discuss the main aim and the main approaches related to this Project. Particular attention is paid to collecting samples, presenting a variety of content-, genre-, composition-related academic texts illustrating typical technical discourses in Ukrainian and English, analysing their typicalities, their genres, composition, structure, language similarities and differences.

Of the top-priority importance are the cross-cultural challenges differentiating texts in different languages as Academic English as a global language of science puts forward a number of challenges in teaching $\mathrm{AE}$ at higher schools in Ukraine primarily because of the sociocultural differences between Ukrainian and English academic discourses, the academic discourse being the text under the conditions of real speech communication with all the variety of extralinguistic factors which cause both its generation and its comprehension by other language speakers. Let's refer to R.B. Kaplan ${ }^{12}$ and O. Tarnopolsky ${ }^{13}$ who described some patterns characteristic for different national cultures and noted the differences between English and Russian models: English academic texts provide for strictly straightforward and consequent utterance of ideas without any deviations: the main idea is revealed at the very beginning; it is supported by arguments - any deviation from the main idea is banned.

In Russian as well as Ukrainian academic texts, associative deviations, revision of different directions, approaches are allowed though they are not connected with the main idea. Today Ukrainian researchers are very active in English academic writing for SCOPUS, and other bases, and it became the top-priority task for them to clearly understand sociocultural differences in academic writing: their scientific ideas could be exceptional, innovative but they are not formatted in accordance with English academic discourse requirements and are rejected.

The discourse approach to conceiving Academic English for science and technology reveals the fact that it extends from peer writing of scientists and

${ }^{12}$ Kaplan R. B. (2001) Cultural thought pattern in intercultural education // Landmark essays on ESL writing/ Ed. by T. Silva and T. K. Matsuda. N.Y. : Hermagoras Press.

${ }_{13}$ Tarnopolsky O. B. (2008) Teaching writing in English for higher school students. Vinnitsa: Nova Kniha. 
technically oriented professionals to the writing aimed at skilled technicians, in between being the types of instructional discourses. Peer writing is exemplified by academic monographs or articles written by experts in one field for other experts in the same field or for experts in the related field. Skilled technicians are also supposed to be experts who lack equivalent training in theory. Instruction discourses refer primarily to teaching texts.

Traditionally, the authors use two terms "rhetoric" and "discourse", to many those being synonymous. But it is important to distinguish rhetoric as the process a writer uses for organizing the data and arguments for specific communicative aims and for specific readers and discourse which is considered to be of higher level. The rhetorical process is best seen operating in fulfilling the specific rhetorical functions in written discourses: description, definition, classification, instructions. The variability of academic discourses is known to be expressed in the research paradigm which is composed of the following elements:1) means of academic co pretension of the object under discussion; 2) linguistic knowledge; 3) specific mental space of the discourse; 4) specific metalanguage. The language picture of the world indicates the depth of the language semiosphere and its resources, its being presented as a mosaic of particular spheres of human academic communication and particular communication situations and roles (oral: discussions, presentations, lectures; written: articles, books, reports, reviews). Cognitive and discursive paradigm, we are basing our analysis on, enables to analyse an academic text as a result of a virtual communication act, as the discourse in static state. Therefore in the processes of comprehending and generating academic texts both linguistic and extralinguistic knowledge is used: information about the object studied, addresser/addressee intentions, virtual communication context etc.

Among a variety of differences between Ukrainian and English academic discourses, we have chosen two: composition and hedges.

Composition. It is universally acknowledged that academic thinking has systemic character which is, to a greater extent, stipulated by text composition, both formal and content-motivated category. Composition unites all text sections causing its logic ties and interdependences. Therefore composition plays an important role in text generation and comprehension, this distinctive category being, in many cases, different from general academic texts in Ukrainian and English, though their basic characteristics coincide: 1) any paragraph begins with the topic sentence which expresses its main idea (topic) and the controlling idea; 2) the topic sentence is followed by supporting statements which explain, illustrate and prove it by examples; the concluding sentence could express some conclusion and connect the paragraph with the following paragraph; 3 ) every paragraph is 
characterised by unity requiring that every sentence in the paragraph is connected with the controlling idea, coherence being necessary for all the sentences following each other in some logical order, and cohesion being the linguistic means of expressing coherence; 4) the structure is composed of 3 main parts: the introductory paragraph, the body and the conclusion; 5) the size of the essay is always indicated ( $120-250$ words); 6) the introductory paragraph should include some general sentences introducing the topic and general statement attracting the readers' attention, the thesis statement, contrary to Ukrainian academic discourses formulating a transparent point of view of the author which is further proved and illustrated; 6) logical and language ties within the body are achieved by the link-words (their exceptional importance is emphasized for any international exam, e.g. Pearson Test of English; 7) the conclusion contains restatement or summary of the main points and final comments in the form of general statements.

In British and American practice they usually pay a special attention to communicative aims in the process of writing essays, articles, reports: description, classification, comparison or contrast, cause and effect, definition, persuasion. And again the difference between Ukrainian and English academic discourses is in very strict orientation to the communicative aim of the English discourse.

The selection of the communicative aim is, in its turn, relates to the selection of genres because they are considered the means of expressing communicative aims. Genre analysis shows a genuine interest in the use of language to achieve communicative aims, and, in this sense, it is not merely an extension of linguistic formalism. Though it does not represent a static description of language, it gives a dynamic explanation of the way expert users of the language manipulate generic conventions to achieve a variety of complex goals, thus uniting the advantages of a sociolinguistic perspective and the advantages of a cognitive perspective, particularly referring to the factual use of language.

And again we should emphasize the fact that it is primarily motivated by applied linguistic concerns, especially language teaching at various levels: it is necessary to develop the knowledge of the code which is the pre-condition for developing communicative expertise in specialist discourse; to provide for obtaining genre knowledge associated with the specialist culture; to acquire sensitivity to cognitive structures of specialist genres. Only then it is possible to become competent users of the discourse of their field, because to participate in any specialist communicative event it is important to understand the communicative aims of any particular discourse and to understand the communicative aim-oriented purposes of the specific use of genres, i.e. to become aware of appropriate rhetorical 
procedures and conventions related to the specialist discourse community they want to join. Thus genre knowledge, procedural knowledge and social knowledge are necessary to produce, distribute and comprehend texts.

After acquiring genre knowledge and understanding the specific rhetorical and conceptual context, it is necessary to become familiar with the language means which are typically used to achieve communicative aims, to adapt to conventions and to become "genre-sensitive". Numerous researches in the study of various academic texts indicated that there are specific lexicogrammatical differences caused by genres, e. g., review (critique) as a typical communicative academic genre is characterised by: a) the communicative aim of representing and evaluating new information and introducing the text which is evaluated into the system of ideas and even revealing intertextual specific features; b) conducting a regulating function; c) availability to trace the ties among the author of the text, the addressor/reviewer and the addressee; d) generalised format. It is the text discussing published information on a scientific topic or issue, collecting the current knowledge on the topic and/or suggesting a new interpretation marshaling evidence to persuade readers that the new interpretation is valid. In spite of the typical aim, general characteristics of review discourses, their compositions somewhat differ in Ukrainian and English texts.

Hedges. Another important aspect of scientific discourse is to weigh evidence and to draw conclusions from the data obtained. Because science is often seen and asserted as an objective discipline, considered as a series of impersonal statements of facts which add up to the truth, any academic discourse is both socially situated and structured to only accomplish rhetorical objectives. In reality, hedging appears to be the linguistic resource which conveys the fundamental characteristics of science, the commentative potentials of any language, the interactive elements which enable to connect the information in the text and the writer's factual interpretation, because one of the fundamental characteristics of science is uncertainty, a kind of scepticism or doubt, i.e. researchers are inevitably express their attitude to the information they describe or prove. In one of the first study of hedges in various discourses J. Lakoff defined them as "fuzzy" words or phrases and stated that they are crucial elements of the academic discourse ${ }^{14,15}$.

Thus hedges reveal the probabilistic nature of science - it is known from the history of science that it was much more deterministic before the second half of the 19th century when the first signs of its probabilistic nature were

\footnotetext{
${ }^{14}$ Lakoff G. (1980) Metaphors we live by. Chicago: Chicago Univ. Press.

${ }^{15}$ Lakoff G. (1996) Moral politics: What conservatives know that liberals don't. Chicago: University of Chicago Press.
} 
noted. In English a completely unhedged writing would not be dealt with seriously, though in Ukrainian or Russian there is no strict limitation as far as hedging as the communicatively oriented mechanism is concerned, e. g. the failure of the experiment is most likely caused by..., the brittleness of this material is least unlikely due to..., the unexpected loss of heat energy seems..., the most likely fracture of a piston, the probable fracture of the assembly line.

Let's illustrate the statements with an example:

"...we might say that engineering is the process of solving a particular kind of problem (involving the control or utilization of the forces of nature) in a particular way (by the application of principles of sciences, mathematics and special problem-solving methods) in order to achieve certain practical desired results. More simply, we might define engineering as the process of harnessing or directing the forces and materials of nature for the use and convenience of man... the word "process" suggests a continuing activity... We can also see that this simple definition clearly points out the basic difference between science and engineering". (A. Nourse, 1962. So you want to be an engineer. - Harper and Brothers, N.Y., pp. 13-14). The extract was cited from L. Trimble's research on the English technical discourses ${ }^{16}$. It is of special interest that showing the technique of adapting original versions he again uses the following: "We might define engineering as the process of harnessing or directing the forces and materials of nature for the use and convenience of man". And again we face the differences in styling in Ukrainian and English academic texts, the former being much more categorical, deterministic and the latter being more hedge-oriented in expressing their conclusions.

Hedging, generally speaking, is considered as the process of reducing and softening categorical statements when the author wants to minimize the risk of imposing his view as the only relevant or valid. They, hedges, are sometimes defined as linguistic cues of bias which are used to avoid personal responsibility for this or that statement, to mitigate responsibility, to express tentativeness or evasiveness.

On the other side, hedges can be used to report or state some results or conclusions which present the addressor's vision of the information but he or she wants to "soften" the strong statement because the experimental data are not available, to mitigate two central positions expressed in scientific writing, to present the acceptance by the international scientific community:

${ }^{16}$ Trimble L. (1992) English for science and technology. A discourse approach. Cambridge: Cambridge Univ. Press. 
researchers do not underestimate their conclusions but they do emphasize that they do not overestimate their results ${ }^{17}$.

Moreover, hedges are also understood as "sophisticated rational strategies" or "humble servants of the scientific community".

Much has also been written about the linguistic classification of hedges. The typical classification can be presented in the following way:

1. Modal verbs or adjectival, adverbial, nominal modal phrases: e. g., may, might, can, could, would, should; possible, probable, likely, unlikely; maybe, perhaps, possibly, probably, likely.

2. Lexical verbs, nouns, adverbs with the meaning of doubting or evaluating: e. g., to seem, to appear, to believe, to assume, to suggest, to indicate, to tend, to argue; claim, assumption, suggestion.

3. Quantifers expressing the approximation of degree, quantity, time: e. g., about, roughly, insignificantly, approximately, generally.

4. Discourse markers which express the author's personal doubt: e. g., in our view, in our opinion.

5. Hedge expressions: e. g., as far as I am concerned, it would probably indicate that.

All of them express personal opinion of the author based on some data or plausible arguments.

The Project we are describing here has also revealed the distributional variability in academic prose, the difference being attributable to variation in the communicative aim both of different genres and different sections within a text. Thus technical review articles are more heavily hedged than research papers: the more powerful the generalization to universality the more hedged the discourse is. The discourses in which their author's argue, persuade, evaluate or appeal to wider audience have more hedged statements than the discourses which inform and describe.

The fact is that generalization causes the author to express judgement, assessment, instruction, e. g., review papers which aim is to supervise a number of relevant works on a particular problem though they are often controversial (scientific articles, patents, essays, synopses, reports specially collected, selected, ordered and analysed). On the other side, research papers require from their authors to suggest some ideas, to advise what to improve while reports, however, present almost pure description.

The frequency in the use of hedges and the variability of their use are also not uniform depending on particular sections of the paper. Thus in the Introduction section the author uses hedges when he wants the reader to

17 Swales J. (1990) Genre analysis: English in academic and research settings. Cambridge: Cambridge University Press. DOI 10.1075/z.184.513swa 
understand that he (the author) proposes some hypothesis, that much has to be done in this field of study, that he is not certain about some results or conclusions. In the Methods section which is descriptive, factual and the least commentative, there are almost no hedges because the statements here are presumably confirmative. A relatively insignificant number of hedges is characteristic for the Result section because method and result sections are rather objective. But Discussion and Conclusion sections are quite opposite due to their subjective discursal nature: the authors are trying to explain, interpret their information or even put forward controversial ideas, explanations, interpretations as if trying to protect themselves from criticism or counter arguments.

To sum up, the comparative academic discourse analysis based on revealing their cross-cultural differences is a relatively new addition to the varieties of discourse analyses available at present but it enables to acknowledge the fact that authentic academic texts are produced and consumed not in isolation but in some real-world context.

\section{CONCLUSIONS}

In the contemporary global world culture, as the activities and ideas, is extremely significant, primarily, because an absence of culturally relevant schemata may lead to feelings of social or cultural dissonance in a variety of political, economic, cultural, educational, academic contacts in multicultural communication. Mass media model the human communicative behaviour and determine the selection of language means: dynamics of changes in nature, society, human concience are immediately reflected in structure and semantics of lexemes, conceptual metaphors accomplishing the important linguocognitive function, and being the result of interaction between human cognition and semantic parametres of every particular language. Therefore they can be used as reliable and efficient devices for the applied comparative cross-cultural analysis. Academic dicourses demonstrate another important field for cross-cultural studies, especially keeping in mind the fact that the English language is the global language for science and technology with its typical resources which are frequently different from other language resources, e. g., hedging is a language resource which are widely used in academic communication, when there is the need to modulate speech acts in order to guarantee a certain level of acceptability and the possibility of coexistence. Hedges in academic discourses are strategic stereotypes, and language users often resort to them to achieve their communicative aims and academic communal adherence, to more cautiously negotiate their claims when referring to other authors' works to anticipate criticism. The primary results obtained in the process of carrying out applied discourse analyses have proved their efficiency and promise to suggest further challenging studies. 


\section{SUMMARY}

The author focuses the attention on cultural literacy and cultural awareness analysing some aspects of mass media and academic discourses, conceptual metaphors and hedges being the instruments for impacting readers and even managing their conscience. The selection of these types of discourses is stipulated by the aims of two cross-cultural projects initiated by the Department of Applied Linguistics of Admiral Makarov National University of Shipbuilding to study the differences in expressing modality of various nature, i.e. by conceptual metaphors in mass media discourses and hedges in academic discourses. It is emphasized that the importance of generating and perceiving English discourses for Ukrainians is primarily motivated by applied linguistic concerns, especially language teaching at various levels.

\section{REFERENCES}

1. Batsevich F. S. (2004) The basics of communicative linguistics. K. : "Academia" Press. (Ukrainian).

2. Bohomolov O. V. (2019) From temptation to discord: the concept of FITNA in Arab Spring discourse // Movoznavstvo, No.1, pp. 3-8. (Ukrainian).

3. Grice P. (1968) Studies in the way of words. - Harvard: Harvard Univ.Press.

4. Hofstede G. (1980).Culture consequences: international differences in work-related values. Beverly Hills: London. DOI 10.1002/bs.3830270213

5. Kaplan R. B. (2001) Cultural thought pattern in intercultural education // Landmark essays on ESL writing/ Ed. by T. Silva and T.K. Matsuda. N.Y. : Hermagoras Press.

6. Karasik V. I. (2002) The language circle: personality, concepts, discourse. Volgograd: Peremena.

7. Khudoliy A. O. (2005) Metaphor in the language of mass media texts. Ostrog: NUOA Press. (Ukrainian).

8. Lado R. (1993) The necessity for systematic comparison of languages and cultures // Landmarks of American language and linguistics, vol. 1. Washington: Materials Development, p. 80.

9. Lakoff G. (1980) Metaphors we live by. Chicago: Chicago Univ. Press.

10. Lakoff G. (1996) Moral politics: What conservatives know that liberals don't. Chicago: University of Chicago Press.

11. Swales J. (1990) Genre analysis: English in academic and research settings. Cambridge: Cambridge University Press. DOI 10.1075/z.184.513swa 
12. Summer W.G. (1999) Cultural relativism // The right thing to do. McGraw Hill.

13. Tarnopolsky O.B. (2008) Teaching writing in English for higher school students. Vinnitsa: Nova Kniha. (Ukrainian).

14. Trimble L. (1992) English for science and technology. A discourse approach. Cambridge: Cambridge Univ. Press.

15. Wierzhbicka A. (1991) Cross-cultural pragmatics. The semantics of human interaction. Berlin - New York: Mouton de Gruyter.

16. Wierzhbicka A. (1992) Semantics, culture and pragmatics. Universal human concepts in culture. Oxford: Oxford University Press.

\section{Information about the author:}

Filippova N. M., $\mathrm{PhD}$ in Philology, Associate Professor at the Department of Applied Linguistics, Admiral Makarov National University of Shipbuilding 9, Heroes of Ukraine Avenue, Mykolaiv, 54025, Ukraine ORCID ID: orcid.org/0000-0002-8840-774X 